Published by LPMP Imperium

Journal homepage: https:/ / ejournal.imperiuminstitute.org/ index.php/ BERDAYA

\title{
Sosialisasi Tentang Investasi Untuk Warga Kembangan Utara Jakarta Barat
}

\author{
Swarmilah Hariani ${ }^{1 *}$, Harnovinsah ${ }^{2}$, Venny ${ }^{3}$ \\ A kuntansi, Fakultas Ekonomi dan Bisnis, Universitas Mercu Buana \\ *Email: swarmilah@mercubuana.ac.id
}

\section{ABSTRACT}

This community service activity is themed "Information about the Capital Market to North Kembangan residents in West Jakarta". The activity is carried out by providing an explanation of the meaning, role, and benefits of the Capital Market in the economy. The history, structure, and institutions related to the Capital Market were explained. The explanation also concerns the basic understanding of trading mechanisms in the Capital Market. The explanation was given by counseling followed by a discussion session, questions and answers from the participants. The results of this activity provide increased knowledge of citizens about the Capital Market, as measured by a questionnaire distributed before and after the activity that contains questions about the Capital Market. The results of the analysis of the questionnaire answers in the form of a comparison of the questionnaire showed a change in public knowledge about capital market investment.

Keywords: capital market investment, financial literacy

\section{BERDAYA}

53

Article History

Received 22 Oct 2019

Revised 8N ov 2019

Accepted $22 \mathrm{~N}$ ov 2019

First Published: 30 N ov 2019

\section{Reviewing Editor}

Donant A. Iskandar, Institut Teknologi dan

Bisnis Kal bis

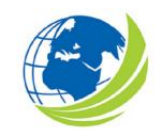

BERDAYA, Vol 1, No.2,

December 2019,

pp. $53-60$

eISSN XXXX-XXXX

To cite this article: Hariani, S., Harnovinsah, H., \& Venny, V. (2019). Sosialisasi Tentang Investasi Untuk Warga Kembangan Utara Jakarta Barat. BERDAYA: Jurnal Pendidikan dan Pengabdian Kepada M asyarakat, 1(2), 53-60

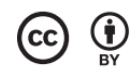

(C) 2019 TheA uthor(s). This open access article is distributed under a Creative Commons Attribution (CC-BY) 4.0 license 


\title{
Sosialisasi Tentang Investasi Untuk Warga Kembangan Utara Jakarta Barat
}

\author{
Swarmilah Hariani ${ }^{1 *}$, Harnovinsah ${ }^{2}$, Venny ${ }^{3}$ \\ A kuntansi, Fakultas Ekonomi dan Bisnis, Universitas Mercubuana \\ JI. Meruya Selatan No.1, RT.4/ RW.1, Meruya Sel., Kec. Kembangan, Kota Jakarta \\ Barat, Daerah Khusus I bukota Jakarta 11650 \\ *Email: swarmilah@mercubuana.ac.id
}

\begin{abstract}
ABSTRAK
Kegiatan pengabdian masyarakat ini bertema Sosialisasi Tentang Pasar Modal pada warga Kembangan Utara di Jakarta Barat. Kegiatan dilakukan dengan memberikan penjelasan tentang pengertian, peran dan manfa at Pasar Modal dalam perekonomian. Dijelaskan pula sejarah, struktur dan lembaga-lembaga terkait dengan Pasar Modal. Penjelasan juga menyangkut pengertian dasar mekanisme perdagangan di Pasar Modal. Pemberian penjelasan dilakukan dengan penyuluhan diikuti sesi diskusi, tanya jawab dari peserta. Hasil kegiatan ini memberikan pengetahuan warga tentang Pasar Modal meningkat, yang diukur dari kuesioner yang dibagikan sebelum dan sesudah kegiatan yang berisi pertanyaan tentang seputar Pasar Modal. Hasil analisis atas jawaban kuestionaire yang berupa perbandingan kuesioner tersebut memperlihatkan adanya perubahan pengetahuan masyarakat mengenai investias pasar modal.
\end{abstract}

Kata Kunci : investasi pasar modal, literasi keuangan

\section{PEN DAHULUAN}

Bagi para ekonom, modal dapat dibagi menjadi modal ekonomi dan modal finansial. Modal ekonomi mencakup tanah, tenaga kerja, bangunan, mobil, traktor, peralatan, dan lainnya. Ini digunakan dalam produksi barang dan jasa untuk konsumsi atau untuk keperluan lain. Modal finansial, sebaliknya, termasuk uang, obligasi, saham / ekuitas, opsi, surat utang, dan lainnya. Yang digunakan untuk membeli modal ekonomi (Acquah-Sam \& Salami, 2013). Pasar keuangan adalah pendorong pertumbuhan dan perkembangan ekonomi, dan memiliki fungsi yang berbeda, yang, jika dilakukan secara efektif, berkontribusi pada pertumbuhan ekonomi dan peningkatan pembangunan dan peningkatan standar hidup (Spaseska et al., 2016).

Pasar saham sebagai segmen paling penting dari pasar modal, memainkan peran penting dalam memobilisasi dana dalam modal pasar. Pasar saham menyediakan platform bagi investor dan peminjam untuk menukar uang dengan menukar saham. Bursa Efek merupakan bentuk pasar terorganisir yang memfasilitasi - peningkatan modal, perdagangan saham yang terdaftar, pengembangan produk, peningkatan peluang untuk investasi investor individu dan institusi, aliran informasi pasar yang bebas dan mendorong budaya dan perilaku perusahaan yang lebih baik. Fitur-fitur pasar modal dan berfungsinya bursa dianggap penting untuk mengembangkan sistem keuangan yang efisien yang dapat menguntungkan ekonomi riil (Prasad Bandi, 2014, p.3).

Pendidikan finansial merupakan tantangan utama di Indonesia. Selain pemahaman perbankan sebagai lembaga pasar uang, pemahaman masyarakat tentang pasar modal saat ini masih belum merata, dan masih banyak yang belum memahami cara berinvestasi di pasar saham. Pasar saham Indonesia adalah investor dibandingkan dengan jumlah penduduk 
Indonesia. Pendidikan finansial sangat penting bagi orang Indonesia untuk meningkatkan ekonomi negara (Nidar \& Bestari, 2012). Hasil survey Lantara dan Kartini (2015) memperlihatkan tingkat pemahaman responden pada literasi keuangan hanya sebesar 45.39 persen dari total sampel 348 responden. Hasil ini relative lebih rendah jika dibandingkan dengan Amerika Serikat (52,87 persen), Australia (53 persen). Didasarkan pada fakta tersebut maka kegiatan ini dilakukan untuk memberikan pengetahuan kepada masyarakat mengenai investasi pasar modal sebagai bagian dari kegiatan pengabdian kepada masyarakat.

\section{Masalah dan tujuan kegiatan}

Upaya yang dilakukan untuk memberikan edukasi kepada anak-anak yang duduk di bangku sekolah dan Perguruan Tinggi adalah dalam rangka mempersiapkan generasi penerus yang akan melanjutkan kegiatan di Pasar Modal di masa-masa yang akan datang sehingga keberlangsungan kegiatan Pasar Modal dapat terjamin, dengan demikian akan mendorong perekonomian menjadi lebih maju demi tercapainya kesejahteraan masyarakat.

Program pengabdian ini hanya memberikan penjelasan atau sosialisasi bagaimana pasar modal di Indonesia, sesuai dengan Undang-Undang Pasar Modal yang berlaku di Indonesia. Tujuan utama dari kegiatan pengabdian pada masyarakat ini adalah memberikan sosialisasi, sehingga diharapkan tercapai peningkatan pemahaman dan pengetahuan dal am pasar modal.

Untuk mencapai tujuan tersebut, maka kegiatan dirumuskan pada tiga poin yaitu:

1. Memberikan Penjelasan Tentang Pengertian, Peran dan Tujuan Pasar Modal dalam Perekonomian Indonesia

2. Memberikan Penjelasan Tentang Struktur Pasar Modal Indonesia, Undang-Undang dan Peraturan Terkait Pasar M odal serta Sejarah Pasar Modal di Indonesia

3. Memberikan Penjelasan Tentang Investasi dan mekanismetransaksi di Pasar M odal Indonesia

\section{Target dan Luaran Kegiatan}

Target kegiatan sosialisasi Pasar Modal pada warga di Jakarta Barat adalah meningkatnya pemahaman warga akan Pasar Modal berkaitan dengan pengertian, peran dan tujuan Pasar Modal dalam perekonomian Indonesia. Pemahaman juga berkaitan dengan sejarah, struktur dan mekanisme perdagangan di Pasar Modal. Pencapaian target tersebut dapat terlihat dari luaran yang berupa jawaban atas kuestionaire yang dibagikan sebelum dan sesudah penyuluhan dimana hasilnya diharapkan meningkat yang merupakan indikator bahwa target tercapai.

\section{Kerangka Pemecahan M asalah.}

\section{MATERI DAN METODE}

Metode kegiatan untuk aktifitas ini adalah Penyuluhan. Kepada peserta diberikan penyuluhan, diajak berdiskusi dan tanya jawab, diberikan questionair sebelum dan sesudah penyuluhan. Sasaran utama Penyuluhan Tentang Sosialisasi Pasar Modal adalah warga Kembangan Utara di Jakarta Barat yang merupakan sekolah berlokasi diseputar Universitas Mercubuana.

\section{M etode Kegiatan.}

Kegiatan Penyuluhan Tentang Sosialisasi Pasar Modal pada warga, bertujuan Memberikan Informasi yang lengkap tentang Pengertian, PerandanTujuanPasar Modal dalamkontribusniaterhadapPerekonomian Indonesia. Materi-materi dalam rangka Sosialisasi 
Tentang Pasar Modal pada warga, diperolehsebagianbesardari Bursa Efek Indonesia dandariberbagai sumber yang rel evan, yang dilakukan dengan cara : ceramah, diskusi dan Tanya jawab.

\section{Mekanisme Evaluasi Kegiatan}

Evaluasi dimaksudkan untuk mengukur apakah terdapat perbedaan yang signifikan pengetahuan tentang Sosialisasi Tentang Investasi UntukWargaKembangan Utara Jakarta Barat,sebelum dan sesudah penyuluhan dilakukan. Karena itu evaluasi dilakukan dengan memberikan questionair sebelum penyuluhan dilakukan dan setelah penyuluhan dilakukan.

\section{Pelaksanaan Kegiatan}

\section{HASIL DAN PEMBAHASAN}

A cara ini dimulai dengan melakukan registrasi dahulu. Peserta kemudian mendapatkan snack, notes, pulpen dan kuesioner. Setelah semua sudah berkumpul kemudian pembukaan acara. Setelah itu pihak PPM Mercubuana melakukan persentasi. Secara etimol ogis, untuk istilah pasar digunakan kata bursa, exchange danmarket. Adapun untuk istilah modal sering digunakan kata efek, securities danstock. Dalam arti sempit pengertian pasar merupakan tempat para penjual danpembeli bertemu untuk melakukan transaksi. A rtinya pembeli dan penjuallangsung bertemu untuk melakukan transaksi dalam suatu lokasi tertentu. Lokasiatau tempat pertemuan tersebut disebut pasar. Namun, dal am arti luas pengertian pasar merupakan tempat melakukan transaksi antara penjual dan pembeli, dimana pembeli dan penjual tidak harus bertemu daam suatu tempat atau bertemulangsung, tetapi dapat dilakukan melalui sarana informasi yang ada seperti saranainformatika.

Kegiatan pengabdian pada masyarakat ini menghasilkan peningkatan pemahaman tentang pengertian, peran dan tujuan Pasar Modal dalam perekonomian Indonesia, struktur dan UU terkait Pasar Modal dan investasi dan mekanisme transaksi di Pasar Modal. Pada awalnya, peserta masih belum jelas apa tentang apa yang dimaksud dengan Pasar Modal. Peserta sangat antusias ketika dipaparkan materi tentang Pasar Modal, terutama terkait dengan mekanisme transaksi di Pasar Modal.

Selama kegiatan tersebut peserta banyak tanya jawab dan dalam pemberian materi, masyarakat banyak bertanya tentang aliran dana masuk merupakan indicator adanya kemungkinan mereka ingin mencoba untuk investasi melalui pasar modal, dimana Pasar M odal merupakan pasar dari berbagai instrument keuangan jangka panjang, sebagai tempat transaksi fihak yang membutuhkan dana dan pihak yang kelebihan dana (investor 


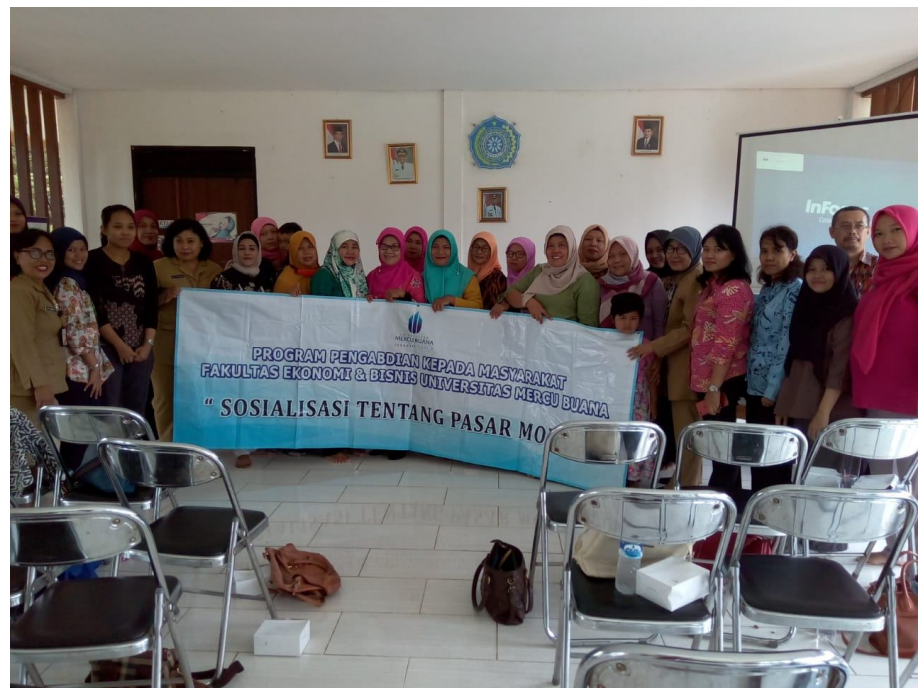

Gambar 1. Photo bersama dalam kegiatan

Sumber: dokumentasi tim pelaksana

Peserta diberikan pemahaman apa saham itu. Peserta sering mendengar di media tetapi kadang masih ragu dalam memahaminya. Kata saham menjadi salah satu kata yang menyeramkan bagi sebagian besar masyarakat Indonesia. Beberapa waktu yang lalu Bursa Efek Indonesia (BEI) mengenalkan sebuah program yang disebut dengan Nabung Saham. BEI mengajak masyarakat untuk berinvestasi secara rutin dan berkala. Sosialisasi Saham ini merupakan ajang pengenalan program baru bagi masyarakat agar paham akan keadaan perekonomian di Indonesia saat ini. Masyarakat antusias mengikuti gelar sosialisasi Saham ini, karena sosialisasi ini merupakan pengetahuan baru yang dapat menguntungkan bagi masyarakat Indonesia. Khususnya masyarakat Meruya Selatan. Investasi saham adalah pilihan investasi yang praktis bagi orang yang sibuk. Dengan Anda membeli saham dapat dikatakan bahwa Anda seperti membeli bisnis namun tidak perlu mengganggu aktivitas utama Anda. Berinvestasi saham tidak mewajibkan Anda untuk datang ke bursa untuk mentransaksikan saham, bahkan Anda tidak perlu keluar rumah untuk melakukan transaksi. Baik transaksi offline maupun online, dapat dilakukan di mana saja, jadi sambil melakukan aktivitas kesibukan Anda, Anda pun dapat sambil melakukan transaksi saham.

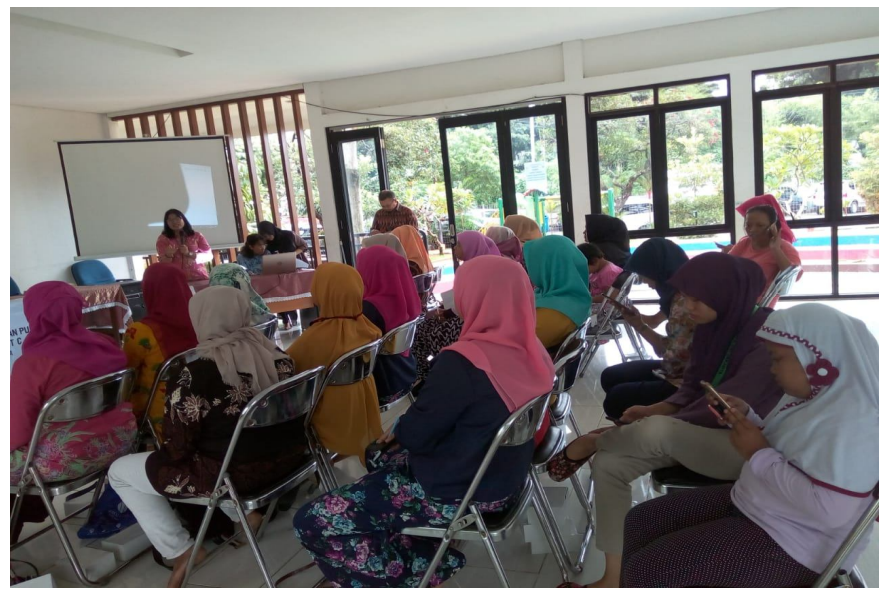

Gambar 2. Pemberian materi mengenai investasi pasar modal Sumber: dokumentasi tim pelaksana 
Setelah selesai acaranya, peserta berkumpul dan berphoto bersama. Peserta sangat senang dan sudah paham mengenai pasar modal. Menambah pengetahuan peserta tentang pasar modal. Sehingga mereka ingin mulai karena penasaran dan ingin mencoba menabung dan mulai mengatur pengelolaan keuangan agar bisa membeli saham.

\section{Evaluasi Kegiatan}

Seluruh perserta menghadiri pelatihan dengan motivasi yang tinggi. Para peserta memberikan tanggapan yang positif terhadap pelatihan sehingga materi bisa disampaikan dengan lancar kepada para peserta pelatihan. Pada dasarnya perlu adanya pengetahuan investasi pasar modal agar masyarakat dapat berinvestasi melalui investasi yang legal dan aktif. Sehingga pada pelatihan ini, masyarakat Kembangan perlu pembekalan keahlian untuk berinvestasi sebagai berikut.

1. Penggunaan analisis fundamental dalam trading saham.

2. Penggunaan analisis teknikal dalam trading saham.

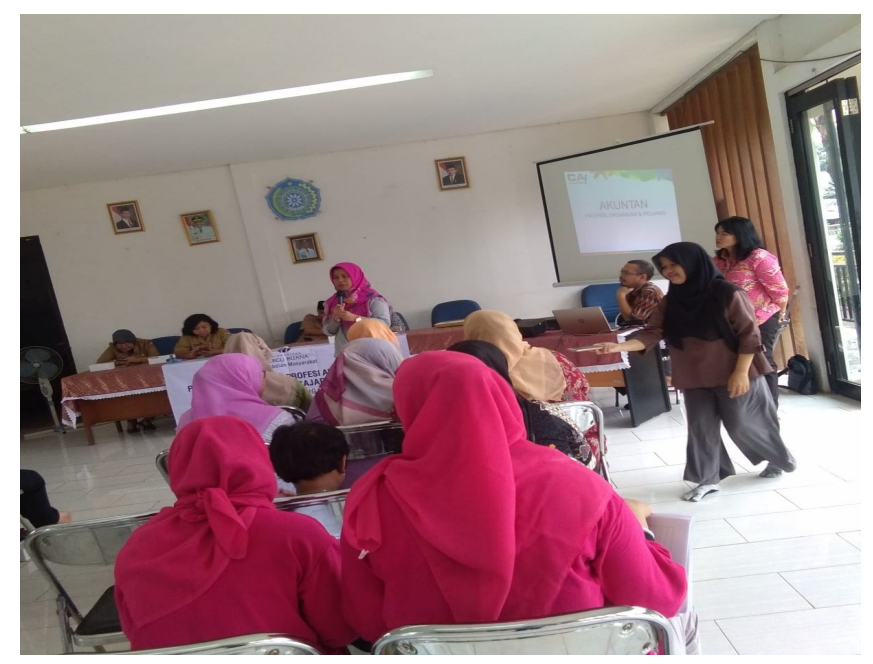

Gambar 3. Diskusi dan tanya jawab

Sumber: dokumentasi tim pelaksana

\section{Kesimpulan}

\section{KESIMPULAN}

Peserta memperoleh manfaat dari Program Pengabdian Masyarakat ini. Manfaat tersebut berupa peningkatan pengetahuan tentang Pasar Modal yang dapat menjadi masukan bagi masyarakat tentang Pasar Modal. Peserta memperoleh informasi bahwa untuk menjadi Investor sangat mudah dan tidak perlu dana yang besar. Sosialisasi Pasar Modal ini juga membantu pemerintah dalam perluasan cakupan sosialisasi untuk mempersiapkan generasi penerus bagi keberlangsungan Pasar Modal di Indonesia.

\section{Saran}

Mengingat bahwa kegiatan ini bermanfaat, maka disarankan untuk diadakan sosialisi di sekolah-sekolah dengan skala yang lebih besar. Sehingga siswa-siswa paham akan saham dan membantu mereka dalam memilih jurusan nantinya disaat mereka akan kuliah. 


\section{REFERENSI}

Acquah-Sam, E., \& Salami, K. (2013). Knowledge and participation in capital market activities: The Ghanaian Experience. International Journal of Scientific Research in Education, 6(2), 189203.

Nidar, S. R., \& Bestari, S. (2012). Personal financial literacy among university students (case study at Padjadjaran University students, Bandung, Indonesia). World Journal of Social Sciences, 2(4), 162-171.

Prasad Bandi, R. (2014, June). Role of Capital Markets and the Stock Exchange. Seminar of Financial Market Development in Myanmar, Nay Pyi Taw, Myanmar Seminar and Briefing Session for Parliamenta, German Ministry of Economic Cooperation and Development (BMZ).

Spaseska, T., Risteska, A., Vitanova, G., Odzaklieska, D., \& Risteska, F. (2016). Analysis of knowledge about capital market activities in Republic of Macedonia. Ekonomika, 62(2), 7183.

Lantara, I. W. N., \& Kartini, N. K. R. (2015). Financial literacy among university students: Empirical evidence from Indonesia. Journal of Indonesian Economy and Business: JIEB., 30(3), 247.

\section{A bout Author}

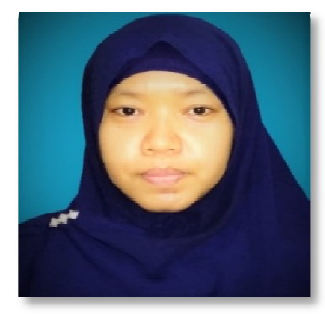

Swarmilah Hariani Batubara, SE.,M.Acc.,CIBA.,CBV, Lahir di Mompang Jae, 31 Maret 1988. Penulis merupakan dosen di Universitas Mercu Buana Jakarta. Saat ini penulis sedang melanjutkan Program PhD di Malaysia. Penulis mengembangkan karirnya sejak tahun 2013 dengan pengalaman mengajar matakuliah Akuntansi Publik. Email: swarmilah@mercubuana.ac.id

\section{FUNDING}

Kegiatan ini merupakan bagian dari program Pengabdian Kepada Masyarakat yang didanai oleh Fakultas Ekonomi dan Bisnis Universitas Mercubuana tahun 2019.

\section{COM PETING INTERESTS}

Tidak ada konflik kepentingan untuk diungkapkan. 
BERDAYA: Jurnal Pendidikan dan Pengabdian Kepada Masyarakat Vol 1, No.2, 2019: 53 - 60 